\title{
Consumer input into research: the Australian Cancer Trials website
}

\author{
Rachel F Dear ${ }^{1 *}$, Alexandra L Barratt ${ }^{2}$, Sally Crossing ${ }^{3}$, Phyllis N Butow ${ }^{4}$, Susan Hanson ${ }^{5}$ and Martin HN Tattersall ${ }^{6}$
}

\begin{abstract}
Background: The Australian Cancer Trials website (ACTO) was publicly launched in 2010 to help people search for cancer clinical trials recruiting in Australia, provide information about clinical trials and assist with doctor-patient communication about trials. We describe consumer involvement in the design and development of ACTO and report our preliminary patient evaluation of the website.
\end{abstract}

Methods: Consumers, led by Cancer Voices NSW, provided the impetus to develop the website. Consumer representative groups were consulted by the research team during the design and development of ACTO which combines a search engine, trial details, general information about trial participation and question prompt lists. Website use was analysed. A patient evaluation questionnaire was completed at one hospital, one week after exposure to the website.

Results: ACTO's main features and content reflect consumer input. In February 2011, it covered 1, 042 cancer trials. Since ACTO's public launch in November 2010, until the end of February 2011, the website has had 2, 549 new visits and generated 17, 833 page views. In a sub-study of 47 patient users, $89 \%$ found the website helpful for learning about clinical trials and all respondents thought patients should have access to ACTO.

Conclusions: The development of ACTO is an example of consumers working with doctors, researchers and policy makers to improve the information available to people whose lives are affected by cancer and to help them participate in their treatment decisions, including consideration of clinical trial enrolment. Consumer input has ensured that the website is informative, targets consumer priorities and is user-friendly. ACTO serves as a model for other health conditions.

\section{Background}

The number of new cancer cases in Australia has more than doubled between 1982 and 2007 [1] and clinical trials are crucial to further progress cancer management and survival. Consumers, led by Cancer Voices NSW (CVN), have campaigned for many years for a national consumer-friendly website about cancer clinical trials which would enable consumers to undertake a comprehensive search for cancer trials recruiting anywhere in Australia and thus to be able to access information about relevant clinical trials. The need for easily accessible, understandable and authoritative information about treatment options, including clinical trials, for consumers has also been acknowledged by Australian Senate

\footnotetext{
* Correspondence: rachel.dear@sydney.edu.au

'Sydney Medical School, Room 391, Blackburn Building, D06, The University of Sydney NSW 2006, Australia

Full list of author information is available at the end of the article
}

Inquiries [2] and in the National Service Improvement Framework for Cancer [3].

Low cancer patient participation in clinical trials may reflect lack of knowledge on the part of both doctors and patients about relevant trials that are recruiting $[4,5]$. Low recruitment rates may also be the result of difficulties faced by doctors in raising the option of clinical trial participation, and by patients in deciding whether to participate [6-8]. Evidence-based strategies are needed to encourage participation in cancer clinical trials [9]. Consumer advocates have been keenly aware of the need to increase clinical participation, seeing consumer-friendly information as key to achieving this goal.

Many patients also want involvement in decisions about their health care. For example, in a heterogeneous sample of cancer patients seeing an oncologist for the first time, $49 \%$ wanted shared decision making and $14 \%$ wanted to take the primary role [10]. To make informed health care

\section{Biomed Central}


choices, including whether to consent to participate in a clinical trial, patients need good information to weigh up their options. This need is reported as a priority by all health consumer advocacy groups.

Up to $60 \%$ of cancer patients use the internet to seek information about cancer, including clinical trials $[11,12]$. Internet-based services to search for and provide information about cancer clinical trials are widely available and consumer input has been used to make these websites more user-friendly $[13,14]$. Online clinical trial matching services have also been developed to help identify potential research participants [15-18]. The results of a number of surveys describe the willingness of people with cancer to search for information about cancer clinical trials on the internet $[12,18-20]$. The quality of information and the user-friendliness of cancer websites vary $[21,22]$. Clearly consumers should be able to access reliable, accurate, accessible and userfriendly web-based information to assist them to participate in decisions about their cancer care.

Effective consumer involvement can contribute to better health care and research and is widely recommended [23-27]. Involvement of relevant stakeholders in the development of websites is a much considered and researched aspect in the field of 'usability' of online health resources [28]. It is generally acknowledged that health communication benefits from materials tailored to the needs of the target audience rather than non-tailored material [29].

To meet the demand for a consumer-friendly cancer clinical trials website, the University of Sydney, Australian New Zealand Clinical Trials Registry (ANZCTR), CVN and Cancer Australia (CA) jointly developed the website called Australian Cancer Trials (ACTO) [30]. It is a notfor-profit national resource for people affected by cancer, doctors and researchers. It provides a search portal for clinical trials, information about clinical trials and trial participation and question prompt lists (QPLs)* (see footnote 1).

We aim to describe the involvement of consumers in the development of ACTO because it is an important resource that has the potential to be replicated for other health conditions. We also present the results of early patient use and reactions to the website.

\section{Methods}

\section{Consumer consultation in the design of the Australian} Cancer Trials website

The development of ACTO was informed by cancer consumers. The word "consumer" is used to mean people affected by cancer. Their involvement in this project meets the key components outlined in the model framework for consumer and community participation in health and medical research developed by the Consumers' Health
Forum of Australia and the National Health and Medical Research Council (NHMRC) [23].

The lead consumer partner was CVN, which had called for a national consumer-friendly cancer clinical trials website for many years. $\mathrm{CVN}$ is an independent peak consumer organisation which works to provide a voice for people affected by cancer [31]. It is a reliable and trusted with a proven track record of involvement in research. For example, in partnership with the Cancer Council NSW it developed and participated in the Consumer Involvement in Research Project which provides a set of cancer consumer criteria which should be applied to research proposals [32] CVN also helped develop and contributes to the Cancer Consumer Advocacy Training Program [33].

The other major consumer partner was the National Consumer Advisory Group (NCAG) which was established in 2007 to help reduce the impact of cancer on Australians. Members of NCAG were recruited by CA [34], a federal government organisation, with the assistance of Cancer Voices Australia and Cancer Council Australia. It consisted of 15 consumers including representatives from the Cancer Voices network, Aboriginal and Torres Strait Islander representatives and three professionals selected to provide advice and guidance to consumers.

The impetus for the website began when SC, the chair of CVN, met with researchers from the University of Sydney at the end of 2006. At this time, it was proposed that the website should be developed using data about registered cancer trials from ANZCTR. In addition, the researchers proposed a formal evaluation of the impact of the website on doctor-patient discussions about trials and accrual rates. Subsequently, in early 2007, SC with representatives from the University of Sydney, ANZCTR and CA formed a research team to apply for a grant from the NHMRC to evaluate the website. In October 2007 it was announced that the grant was successful.

In her role as a research team principal investigator, SC contacted by email the Cancer Voices chairpersons from six Australian states and the Australian Capital Territory asking them to nominate existing cancer trials websites favoured by cancer consumers, key website design features and the information required for a consumer-friendly website. Three responses were received (from Cancer Voices South Australia, Victoria and New South Wales) and reported verbally at a meeting in October 2007. SC recorded their views in a summary report.

Concurrently during 2007, through NCAG's Cancer Voices membership, the development of a consumerfriendly website for CA was identified as a priority at the first meeting of NCAG. Subsequently, in consultation 
with ANZCTR, CA developed a background paper that included a table of current information collected about clinical trials from registrants and displayed on ANZCTR. From March until May 2007 the background paper was circulated to 50 consumers from across Australia from CA's network including young people affected by cancer. Consumers were requested to identify: 1 ) which of the data elements already available on the ANZCTR should be displayed on a consumer-friendly website and 2) what additional information would be required to assist consumers in making decisions about cancer clinical trials.

Twenty-one responses were received and collated into a report. In the report, two tables were provided: 1) a list of all the data elements consumers would need about each cancer trial to help make an informed decision and 2) additional consumer cancer items that needed to be collected by ANZCTR to satisfy consumer needs. In addition, the process of collecting and transferring data from ANZCTR to the consumer-friendly website was proposed.

The second NCAG meeting in October 2007 provided the opportunity to announce the NHMRC funding and for $\mathrm{SC}$ to present her summary report. An update was given by NCAG about their input into the website's development. To ensure that a consumer-friendly cancer clinical trials website would be achieved, CA entered into a partnership with ANZCTR and the research team. Work was progressed at the end of 2007 with the formation of a Cancer Clinical Trials Website Consumer Reference Group which had members from CVN, CA and NCAG.

This group met in January 2008 to further discuss 1) the terms from the clinical trial registries that should be extracted for display on ACTO; 2 ) the additional cancer items needed from researchers; and 3) a conceptual outline for ACTO. Draft website pages were designed and specific data elements to be included on each page were identified. Information fields were chosen that reflected the recommendations of the collated consumer views about what would be helpful for people to make informed decisions about participating in a cancer clinical trial. Consumers also listed what they considered to be essential elements of the search engine for the site. These findings were reported to the research team which, from 2008, proceeded with the website's development in consultation with CA, ANZCTR and a website development company.

Consumers consistently identified that a lay summary was an essential component in the display of information about each trial. As a result, consumers and researchers tested a method to develop standardised lay summaries. In June 2008, five members of the research team wrote lay summaries for 146 cancer trials already registered on the ANZCTR. Eleven Cancer Voices NSW consumer representatives, who had undertaken the Cancer Council NSW's Consumer Involvement in Research
Training Program (a 2-day intensive training program in research methods and the application of lay criteria to evaluate research protocols) [35] critiqued these summaries. Their feedback indicated that the quality of the lay summaries was mixed. Their overwhelming recommendation was that the project should employ a professional medical writer to ensure that summaries would be consistent in style, phraseology and level of complexity.

Consumers agreed that the overall purpose of ACTO was that it should be a comprehensive source of cancer clinical trials in which consumers in Australia might enrol. The general principles that guided this website design were that it should be easy to read, use simple language, have a clear format with minimal colour and without distractions, be easy to navigate and quick to load. The CancerHelp UK [36] and the National Cancer Institute [37] websites were identified as consumerfriendly cancer clinical trial websites that were used to guide the development of ACTO.

\section{ACTO Evaluation}

From June 2008 to October 2010 ACTO was the subject of a large cluster randomised trial. Its aim was to evaluate the effect of the website on discussions between patients and medical oncologists about participation in cancer clinical trials and recruitment rates to trials. Thirty medical oncologists from 30 clinics in two Australian states (New South Wales and Victoria) and 493 patients with cancer were recruited (full evaluation data to be reported elsewhere). We conducted a sub-study that recruited patients from one medical oncologist working at a major teaching hospital in Sydney, Australia. This sub-study was completed specifically to collect the views of an unselected sample of cancer patients about the website. These patients were asked to complete an online questionnaire (Q1) which asked demographic questions before their scheduled appointment with their medical oncologist. After completing this questionnaire, all patients were automatically redirected to ACTO. One week after their consultation patients were asked to complete a second online questionnaire (Q2) which asked for reactions to the website. User and hit statistics were obtained by log file analysis using Google Analytics [38].

Statistical analyses were performed using the standard package SAS (version 9, SAS Institute, Cary, NC, USA). The study was approved by of the University of Sydney (Sydney, Australia) and Royal Prince Alfred Hospital (Sydney, Australia).

\section{Results}

\section{The Australian Cancer Trials website}

The components of ACTO that are a result of consumer consultation are described. 
Figure 1 is a screen shot showing the main features of the ACTO home page. These features include 1) A search function; 2) Information about each clinical trial; 3) Supporting information about clinical trial participation; and 4) QPLs.
As guided by consumers, ACTO meets HealthInsite Information Partner requirements [39]. HealthInsite is a federal government initiative which aims to provide access to high quality information about health care to Australians.

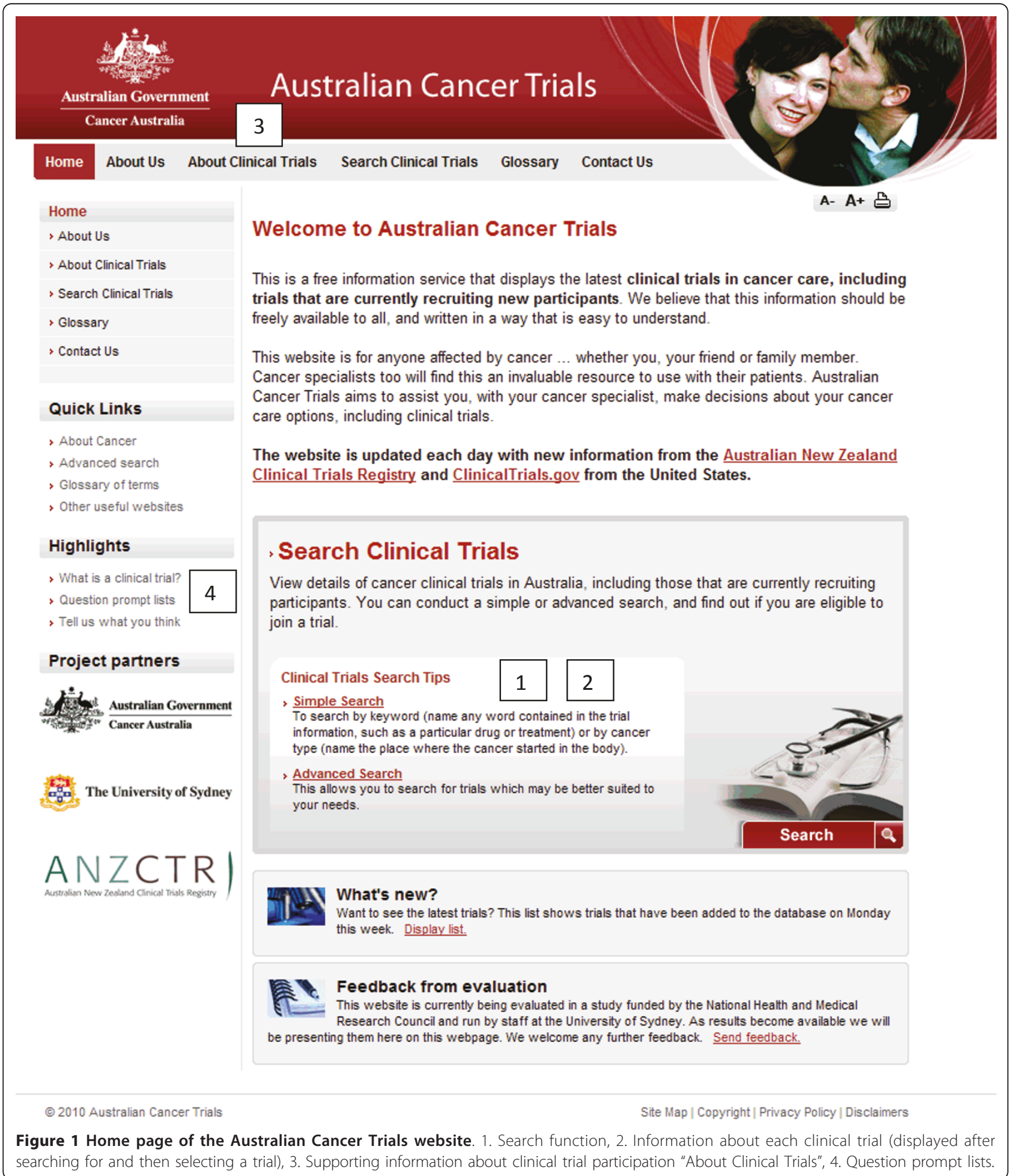




\section{Source of cancer clinical trial information}

Consumers supported the research team's novel idea to use ANZCTR, which registers clinical trials, to automatically download cancer trial information to ACTO. However, it was established that only one-third of cancer trials conducted in Australia are registered with the ANZCTR and approximately two-thirds are registered with the US trial registry, ClinicalTrials.gov (CT.gov). Thus, for ACTO to satisfy consumer demands for a single portal of cancer clinical trials recruiting in Australia, data needed to be sourced from both of these registries.

To achieve this, the content for ACTO is extracted directly from ANZCTR and CT.gov via their data exporting services and downloaded to ACTO on a weekly basis. In contrast, static content (the content which is unchanged week to week) is controlled by Umbraco which is a content management system for publishing content on the Internet. This content is only reviewed and updated occasionally.

\section{Cancer trial search function}

As of March 2011 1, 040 cancer clinical trials are displayed on ACTO and approximately eight new trials are added every month.

The elements of the search function that consumers identified as important were 1) it should be easy to use even by those without much computer experience; 2) a simple and an advanced search function and; 3 ) the simple search should have a drop down list of cancer types available.

The simple search page allows users to search by either keyword (eg recurrence, early cancer) or cancer type (using a drop-down list). The advanced search page allows users to refine their search according to cancer stage, phase of trial, recruitment status (open or closed) and location of recruitment.

Consumers requested a facility for users to register for email alerts of newly registered trials or updates about a specific trial. ACTO is working towards providing this service.

\section{Information displayed about each clinical trial}

The information displayed about each trial on ACTO is shown in Table 1. All of these items were identified as essential by consumers. Most of these details are sourced from routinely collected data provided by trial registrants on ANZCTR and CT.gov.

It is important to note that a lay summary of the trial, cancer stage, anticipated end date for a trial, the cancer treatment type, specific location of recruitment, time, cost and travel commitments and the side effects of the treatments in the trial are not routinely collected by trial registries. To obtain this data, which was additional information requested by consumers, a separate module of "additional cancer items" was developed specifically for registrants of cancer trials on ANZCTR (Table 2).
Table 1 Data items about each trial that are displayed on the Australian Cancer Trials website

\begin{tabular}{ll}
\hline & Data items \\
\hline 1. & Public title \\
2. & Recruitment status \\
3. & Phase of trial \\
4. & Cancer stage* \\
5. & Lay summary written by a medical writer* \\
6. & Description of the study \\
7. & Target sample size \\
8. & Primary outcome \\
9. & Secondary outcomes \\
10. & Side effects \\
11. & Inclusion criteria (includes age, gender, health volunteers) \\
12. & Exclusion criteria \\
13. & Recruitment dates \\
14. & Cost and time commitments* \\
15. & Location of trial* \\
16. & Ethics approval \\
17. & Contacts for public and research queries \\
18. & Trial sponsor(s) \\
19. & Funding source(s) \\
\hline Displated if a registrant of a cancer trialon the Australian New Zealand
\end{tabular}

*Displayed if a registrant of a cancer trial on the Australian New Zealand Clinical Trials Registry completes the additional cancer items (Table 2).

Now, when a cancer trial is registered on ANZCTR, the registrant is encouraged to provide this additional information because it enhances the consumer-friendliness of the trial information when it is displayed on ACTO.

Consumers felt it was important that the website should include Phase 1, 2 and 3 cancer trials as well as closed trials. Including phase 1 trials was considered particularly important for patients with no further standard treatment options. Closed trials are those closed to recruitment with follow-up continuing, or with completed follow-up. Including closed trials means that patients who enrolled in these trials are still able to see the trial on ACTO, and may enable access to trial results.

In response to the consumer feedback described, all lay summaries have been rewritten by a medical writer who continues to write summaries for new trials as they are registered. Summaries (and the website's supporting information) are written for a reading age of approximately fourteen years.

Supporting information about clinical trial participation Supporting information about clinical trial participation (the "About Clinical Trials section of the website) was informed by consumer recommendations (obtained as described above) and reviewed by the ACTO research team and a medical writer. It includes:

- What clinical trials are and their purpose

- The informed consent process

- Ethical issues 
Table 2 Additional cancer items collected by Australian New Zealand Clinical Trials Registry from registrants of cancer trials

\begin{tabular}{|c|c|}
\hline Data item & Options \\
\hline \multirow[t]{4}{*}{ Cancer stage } & Early \\
\hline & Locally recurrent or locally advanced \\
\hline & Metastatic/Widespread \\
\hline & Not applicable \\
\hline \multirow[t]{13}{*}{ Treatment type (s) } & Treatment: Hormones \\
\hline & Treatment: Chemotherapy \\
\hline & Treatment: Targeted therapies and biological therapies \\
\hline & Treatment: Radiotherapy \\
\hline & Treatment: Surgery \\
\hline & Treatment: Other \\
\hline & Antiemetics \\
\hline & Complementary \\
\hline & Palliative care \\
\hline & Prevention/Screening \\
\hline & Psychosocial (counselling/training/communication/education) \\
\hline & Lifestyle \\
\hline & Rehabilitation \\
\hline State (s) of recruitment & The Australian state (s) where the participants are being recruited \\
\hline $\begin{array}{l}\text { Anticipated or actual recruitment } \\
\text { end date }\end{array}$ & The anticipated or actual date the trial will stop recruiting patients \\
\hline Side effects & The known and possible side effect (s) for each trial arm from most to least common \\
\hline \multirow[t]{3}{*}{ Cost to participants } & Similar cost as usual care \\
\hline & Less cost than usual care \\
\hline & More cost than usual care \\
\hline \multirow[t]{3}{*}{ Time commitments } & Similar time commitment as usual care \\
\hline & Less time commitment than usual care \\
\hline & More time commitment than usual care \\
\hline \multirow{4}{*}{$\begin{array}{l}\text { Lay summary written by a medical } \\
\text { writer }\end{array}$} & Format of summary: \\
\hline & - An initial sentence summarizing the trial purpose \\
\hline & - A section describing the patient eligibility under the heading "Who is it for?" \\
\hline & $\begin{array}{l}\text { - A section entitled "Trial details" which describes the trial design, intervention(s) and comparator(s) and } \\
\text { outcome measures of the trial }\end{array}$ \\
\hline
\end{tabular}

- How a person or a hospital/treatment centre goes about becoming part of a trial

- Assessment issues (eligibility)

- Risks and benefits of participating in a trial

- The process of dissemination of trial results

Permission was obtained from CancerHelp UK to use their glossary for ACTO. Over time, this has been added to and modified.

ACTO contains two QPLs because they were identified as a priority area for consumers at the first NCAG meeting in March 2007 and have been shown to prompt questionasking and increase the likelihood of people having their information needs met [40]. Of the two QPLs developed for the website, one is designed to help consumers ask general questions about clinical trial participation
('General question prompt list: Should I consider joining a clinical trial', Table 3) and the second is a specific QPL called "Should I consider joining this clinical trial?" Both reflect consumer recommended questions and aim to help consumers ask specific questions about a trial that is relevant to their current clinical circumstances. There is a link to the general QPL on the home page of ACTO. A link to the specific QPL is provided next to each clinical trial ("What questions do you need to ask about this clinical trial?"). Hyperlinks are provided from each question to areas on the website that help to answer each question. The QPLs can be printed. Consumers are advised to discuss the QPLs with their cancer specialist.

\section{Website access}

ACTO is currently hosted by CA. Consumer organisations are playing an integral role in the promotion and 
Table 3 General question prompt list: should I consider joining a clinical trial?

\begin{tabular}{|c|c|}
\hline Question category & Questions \\
\hline Understanding my treatment choices & $\begin{array}{l}\text { 1. What is the usual (standard) treatment for my condition? } \\
\text { 2. How do I find a suitable clinical trial? } \\
\text { 3. Who can join? } \\
\text { 4. How do I take part? } \\
\text { 5. How will my confidentiality be protected? }\end{array}$ \\
\hline Finding out about a trial & 1. How can I learn more about the trial which interests me? \\
\hline Understanding the possible benefits & $\begin{array}{l}\text { 1. What benefits could I get by joining a trial? } \\
\text { 2. If I join a trial, how might others benefit? }\end{array}$ \\
\hline Understanding the possible risks & $\begin{array}{l}\text { 1. What are the general risks of being in a trial? } \\
\text { 2. If I get a side effect or injury because of being in the trial, will I get } \\
\text { compensation? }\end{array}$ \\
\hline $\begin{array}{l}\text { The differences between going on the trial and having } \\
\text { standard treatment }\end{array}$ & $\begin{array}{l}\text { 1. What are the usual costs of being in a trial and how does this differ from } \\
\text { standard treatment? }\end{array}$ \\
\hline $\begin{array}{l}\text { Types of clinical trials and understanding 'randomisation' and } \\
\text { 'blinding' }\end{array}$ & $\begin{array}{l}\text { 1. What types of clinical trials are there? } \\
\text { 2. What does randomisation mean? } \\
\text { 3. What does blinding mean? }\end{array}$ \\
\hline Understanding my right to join or not to join the trial & $\begin{array}{l}\text { 1. Will my doctor still treat me if I decide not to go on a trial? } \\
\text { 2. Do I have time to think about whether to go on a trial (a day or two, or a } \\
\text { week?) } \\
\text { 3. If I join the trial, but later change my mind, how can I stop? } \\
\text { 4. Will I be penalised in any way? }\end{array}$ \\
\hline Results of the trial & $\begin{array}{l}\text { 1. How will I be informed of the results of a trial? } \\
\text { 2. How are the results measured? }\end{array}$ \\
\hline
\end{tabular}

Underlined statements indicate hyperlinks to enable website-users to find the answers to these questions on the Australian Cancer Trials website

dissemination of ACTO through consumer newsletters and website links, email alerts, consumer organisation forums and multi-disciplinary conferences.

\section{Australian Cancer Trials website evaluation Access statistics}

To comply with the trial protocol the site was not promoted during the trial period from December 2008 until October 2010 so access statistics are reported from 1 November 2010 until 28 February 2011. 2, 549 unique visitors during this period visited the website a total of 3,342 times ACTO and generated 17, 833 page views. There were an average of 5 pages viewed at each visit and the mean visit duration was 3.4 minutes (range from 1 minute to 13 minutes). A planned promotional program will commence in April 2011 so it expected these numbers will increase.

\section{Patient evaluation}

The 99 patients in the sub-study had a mean age of 53 years and $70 \%$ were female. Twenty-nine percent of patients had breast cancer, $20 \%$ had sarcoma, 13\% had ovarian cancer and $38 \%$ had other cancer types. Of those completing the questionnaires 47 out of 80 (59\%) patients responded that they looked at the website. Their feedback about the website is displayed in Table 4. Seventy percent of patients thought the search function was easy to use, $89 \%$ thought ACTO was helpful for learning more about cancer clinical trials and all patients thought that it was important for patients to have access to ACTO.

\section{Discussion}

The development of ACTO is an exemplar of a partnership between consumers, clinical researchers and policy makers to create an informative national resource about cancer clinical trials for people affected by cancer, doctors and researchers.

Although they contain valuable information, trial registry websites are not always intuitive to use and are technical in nature. They do not contain related information about clinical trial participation such as a glossary and descriptive information about clinical trial participation. Subsequently, ACTO has been developed using trial registry data, to meet consumers' demands for a comprehensive user-friendly portal of cancer clinical trials recruiting in Australia. It also provides supporting information that can assist them in the decision-making process to join a trial. To be comprehensive, ACTO obtains trial data from both ANZCTR and CT.gov. Sourcing data directly from these clinical trial registries is a unique feature of ACTO and is unlike CancerHelp UK, and the National Cancer Institute both of which maintain their own databases of trials. This important feature increases the efficiency of the website, minimises costs, avoids duplication, and provides good coverage of clinical trials. Furthermore consumers wanted the same source of data to be available to health professionals and the general public. To address all the information consumers considered essential to making a decision about participating in a trial, ANZCTR collects the "additional cancer items" about registered cancer trials 


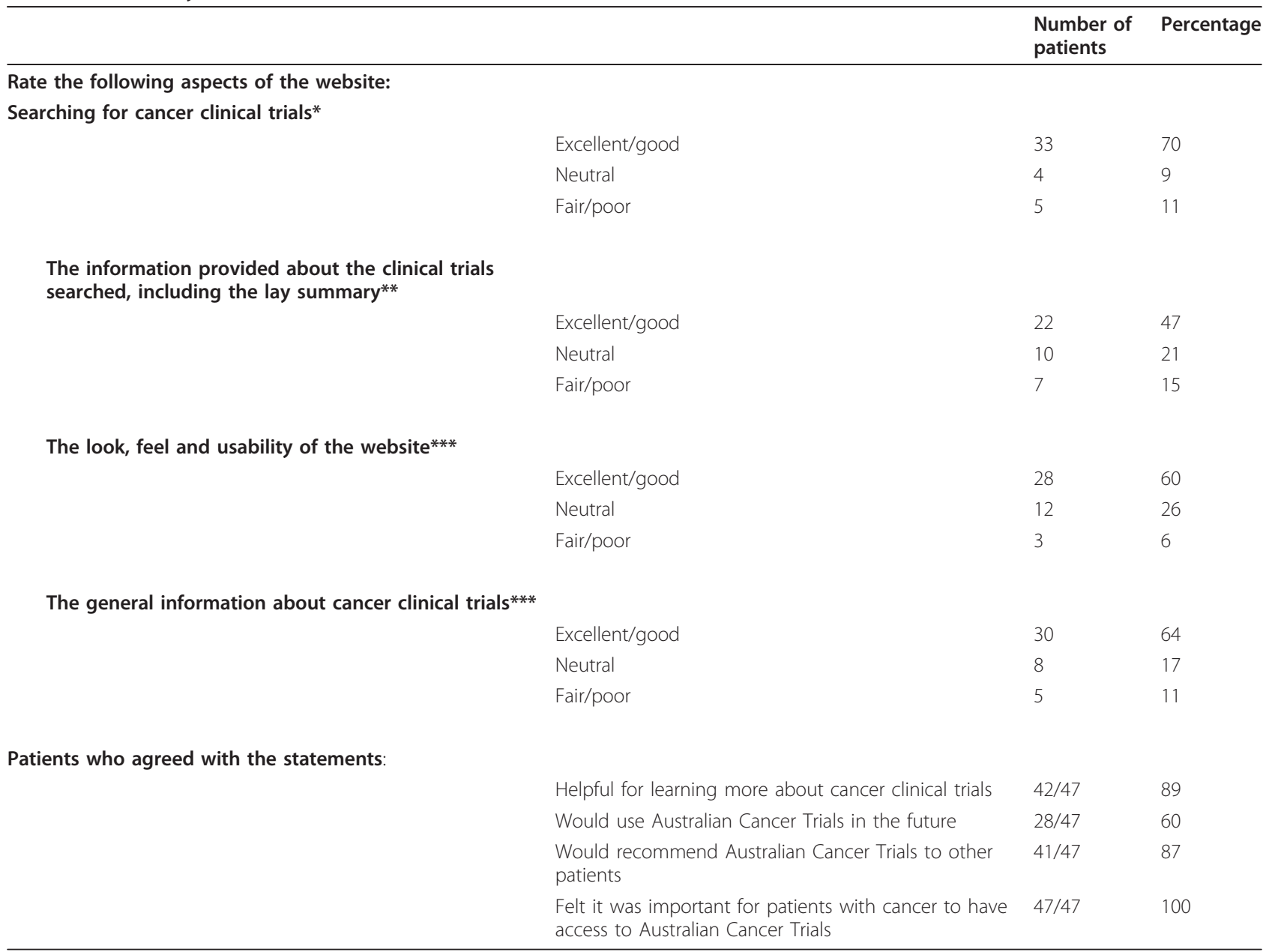

* 5 did not answer ** 8 did not answer *** 4 did not answer.

especially for ACTO. The Australian Cancer Trials website's features that were informed by consumer-input are summarised in Table 5. Consumer-friendly websites in other health conditions could be developed using a similar model. We note that in 2011 the National Institute for Health Research developed the UK Clinical Trials Gateway which provides easy to understand information about clinical trials in all health conditions using CT.gov and the International Standardised Randomised Controlled Number Register [41,42].

To answer consumer information needs QPLs have been developed to help patients make informed health care choices [40]. Currently, there are no generic question prompt lists to help consumers considering clinical trial participation. ACTO is unique because it offers two question prompt lists for people considering clinical trial participation, one generic and the other specific to the trial in question. These were modelled on a QPL which had been developed by some of the study team members for a large international breast cancer clinical trial [43]. The importance of asking doctors these questions is highlighted on the website.

Worldwide, other cancer clinical trial websites have had consumer input. The evolution and improvement of the NCI's online cancer information has been "user-driven" from the launch of CancerNet in 1995 to the development of the current NCI website [14]. The NCI has used multiple approaches to gathering input including stakeholder meetings, focus groups, online user surveys, usability testing and search log analysis. Both the NCI website and CancerHelp UK have recently upgraded their websites based on consumer feedback. An advisory board consisting of breast cancer experts and representatives from patient support and advocacy organisations assisted with the development of a German breast cancer trials website [18].

Existing cancer clinical trial websites may have deficiencies. The website content maybe limited, hard to understand and often require users to have high literacy levels $[21,22,44]$. Websites can be hard to navigate [22]. 


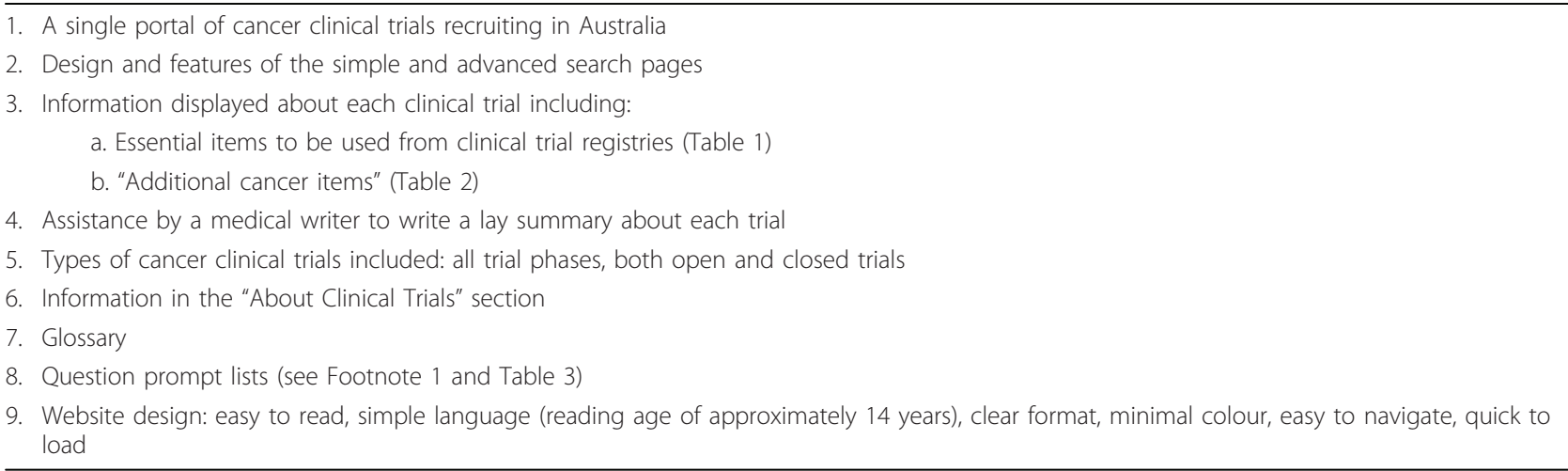

Online cancer clinical trial search tools may be complex [16] and do not encourage users to consult their doctors. As a result, these websites may not be fulfilling their potential to meet consumers' information needs.

The evidence from our study is that ACTO has overcome these deficiencies. Although the initial evaluation was limited by a small sample, most patients found it easy to search for clinical trials. There appears to be sufficient information on the website. It was encouraging that all respondents thought that it was important for patients to have access to ACTO. People are spending 3.4 minutes on average browsing ACTO, which is similar to the time spent by users of a German breast cancer trials website (mean visit duration 3.2 minutes) [18] and more than the time estimated that most people look at websites [45].

ACTO has some limitations. ANZCTR and CT.gov depend on researchers to provide accurate and up-todate information about registered trials [46]. Despite being a precondition for publication in an International Committee of Medical Journal Editors journal, not all clinical trials are registered, so it is likely that ACTO does not display every trial that is recruiting in Australia. Furthermore, if the additional cancer items are not provided by registrants of cancer trials on the ANZCTR, the trial will appear on ACTO, but these additional fields will be blank. Similarly not all the additional cancer items can be sourced from CT.gov, highlighting differences in data collection across clinical trial registries. Every effort is being made to encourage registrants to contribute this important information so that it can be made available on ACTO.

Consumer involvement in health care may include participation in research agenda setting [24], evaluating research hypotheses [47], informally or formally evaluating grant proposals [35,48-50], communicating results and supporting the incorporation of research findings into practice $[51,52]$. The development of ACTO has benefited from consumer involvement in each of these areas: they have helped set the agenda for this initiative, helped obtain research grant funding for the evaluation of ACTO and contributed to the website's development and design. In collaboration with $\mathrm{CA}$, who is continuing to fund the website, consumers led by $\mathrm{CVN}$ are playing an essential role in advising about the website's promotion and future enhancements. For example, in collaboration with the research team, they have developed a promotional plan which aims to make the relevant stakeholders aware of ACTO using print media, journal articles, letters, advertisements, posters and bookmarks. Consumers have obtained a more detailed knowledge of trial registries and a closer relationship with the research community as a result of their involvement. The project has enabled opportunities for connections and information exchange between independent consumer organisations (CVN), government organisations (CA and NCAG), ANZCTR and the University of Sydney.

Although the development of a website required technical input, this did not hinder consumer involvement. The research team helped consumers liaise with technical experts so that consumers' desire for easily accessible data about clinical trials could be achieved. In summary, the critical success factors of this project were: (1) that the research team has worked with well-recognised consumer groups with extensive networks; (2) it was determined that a consumer-friendly cancer clinical trials website was a priority for consumer groups and their members and this was supported by the research team; (3) the research team listened to the needs of consumers' and responded to their needs; and (4) the research team assisted consumer groups to provide input when necessary.

\section{Conclusions}

ACTO allows user-friendly access to the information contained in two clinical trials registries, the ANZCTR and CT.gov. Its development is an example of consumers working with doctors, researchers and policy 
makers to improve the information available to people whose lives are affected by cancer and to help them participate in their treatment decisions, including consideration of clinical trials. Consumer advocacy and input is critical to successful and relevant information resources and has ensured that the website is informative, targets consumer priorities and is user-friendly. ACTO can serve as a model for other health conditions.

\section{List of abbreviations used}

ACTO: Australian Cancer Trials website; ANZCTR: Australian New Zealand Clinical Trials Registry; CA: Cancer Australia; CVN: Cancer Voices New South Wales; CT.gov: ClinicalTrials.gov; NCAG: Cancer Australia's National Consumer Advisory Group; QPL: Question prompt list; SC: Sally Crossing. *Footnote 1: A question prompt list is a structured list of questions for the patient, or their caregiver, to ask their doctor (or other health professional), if they wish.

\section{Acknowledgements and Funding}

The development of a consumer website about cancer clinical trials has been made possible through the collaborative efforts of consumers in partnership with the University of Sydney, the Australian and New Zealand Clinical Trials Registry and Cancer Australia. The authors also wish to thank Anne Cullinan, a medical writer, who has made a considerable contribution to the Australian Cancer Trials website.

The Australian Cancer Trials website was funded by Cancer Australia with partial funding from the National Health and Medical Research Council project grant (grant reference number 512380).

\section{Author details}

'Sydney Medical School, Room 391, Blackburn Building, D06, The University of Sydney NSW 2006, Australia. ${ }^{2}$ Sydney School of Public Health, The University of Sydney, Sydney, Australia. ${ }^{3}$ Cancer Voices NSW and Breast Cancer Action Group NSW, Sydney, Australia. ${ }^{4}$ School of Psychology, The University of Sydney, Sydney, Australia. ${ }^{5}$ Cancer Australia, Melbourne, Victoria, Australia. ${ }^{6}$ Department of Medicine, The University of Sydney, Sydney, Australia.

\section{Authors' contributions}

RFD made the major contribution to the manuscript's concept and design, coordinated the project to develop the website, conducted the acquisition, analysis and interpretation of data and drafted the manuscript. AB, SC and MT contributed to the manuscript's concept and all authors revised the manuscript critically. All authors have given approval of the final manuscript.

\section{Authors' information}

SC is the Chair of Cancer Voices NSW and Founding Chair of Breast Cancer Action Group NSW. Both groups provide a voice for people affected by cancer wherever decisions impacting them and their treatment are made, for example in government, health service provision, research, support and care services. Since 2000 Cancer Voices NSW has provided the independent voice of people affected by cancer and is active in the areas of diagnosis, information, treatment, research, support and care, working in partnership with providers of these services, ensuring the patient perspective is heard. $\mathrm{SH}$ is the national manager for consumer support at Cancer Australia. Cancer Australia was established by the Australian Government to guide improvements in cancer services and research in Australia. Cancer Australia's National Consumer Advisory Group's priorities are to improve consumer information about cancer services, facilitate involvement and choice in treatment options and strengthen quality support for people affected by cancer. RFD, PB, AB and MT are researchers with the Centre for Medical Psychology and Evidence-Based Decision-Making (CeMPED) at the University of Sydney. CeMPED supports research to answer questions about ways to assist patients to be more involved in their own health care.

\section{Competing interests}

The authors declare that they have no competing interests.
Received: 14 April 2011 Accepted: 26 June 2011

Published: 26 June 2011

\section{References}

1. Australian Institute of Health and Welfare. [http://www.aihw.gov.au/ cancer].

2. Senate Community Affairs Committee: The cancer journey: informing choice, in Report of the Inquiry into services and treatment options for persons with cancer. Australian Government; Canberra; 2005, 1-169.

3. National Health Priority Action Council (NHPAC): National Service Improvement Framework for Cancer. Australian Government; Canberra; 2006, 1-92.

4. Embi PJ, Jain A, Clark J, Bizjack S, Hornung R, Harris CM: Effect of a Clinical Trial Alert System on Physician Participation in Trial Recruitment. Arch Intern Med 2005, 165(19):2272-2277.

5. Abraham NS, Young JM, Solomon MJ: A systematic review of reasons for nonentry of eligible patients into surgical randomized controlled trials. Surgery 2006, 139(4):469-483.

6. Fallowfield LJ, Jenkins V, Brennan C, Sawtell M, Moynihan C, Souhami RL: Attitudes of patients to randomised clinical trials of cancer therapy. Eur $J$ Cancer 1998, 34(10):1554-1559.

7. Solomon M, McLeod R: Surgery and the randomised controlled trial: past, present and future. Med J Aust 1998, 169:380-383.

8. Mills EJ, Seely D, Rachlis B, Griffith L, Wu P, Wilson K, Ellis P, Wright JR: Barriers to participation in clinical trials of cancer: a meta-analysis and systematic review of patient-reported factors. The Lancet Oncology 2006, 7(2):141-148.

9. Mc Daid C, Hodges Z, Fayter D, Stirk L, Eastwood A: Increasing participation of cancer patients in randomised controlled trials: A systematic review. Trials 2006, 7.

10. Butow P, Devine R, Boyer M, Pendlebury S, Jackson M, Tattersall MH: Cancer consultation preparation package: changing patients but not physicians is not enough. J Clin Oncol 2004, 22(21):4401-4409.

11. Health Information National Trends Survey. [http://hints.cancer.gov/ questions/section1.jsp? section=Internet+Use]

12. Castleton $K$, Fong $T$, Wang-Gillam A, Waqar MA, Jeffe DB, Kehlenbrink $L$, Gao F, Govindan R: A survey of Internet utilization among patients with cancer. Support Care Cancer 2010

13. Improving the usability of the CancerHelp website. [http://www. minervation.com/index.aspx?o=1149\&newsitem $=2106]$.

14. Grama LM, Beckwith M, Bittinger W, Blais D, Lollar C, Middleswarth A, Noone M, Price D, Quint-Kasner S, Shields V: The role of user input in shaping online information from the National Cancer Institute. J Med Internet Res 2005, 7(3):e25.

15. Allison M: Can web 2.0 reboot clinical trials? Nat Biotechnol 2009, 27(10):895-902.

16. Atkinson NL, Massett HA, Mylks C, Hanna B, Deering MJ, Hesse BW: Usercentered research on breast cancer patient needs and preferences of an Internet-based clinical trial matching system. J Med Internet Res 2007, 9(2): e13.

17. Metz JM, Coyle C, Hudson C, Hampshire M: An Internet-based cancer clinical trials matching resource. J Med Internet Res 2005, 7(3):e24.

18. Wallwiener M, Wallwiener CW, Brucker SY, Hartkopf AD, Fehm TN, Kansy JK: The Brustkrebs-Studien.de website for breast cancer patients: User acceptance of a German internet portal offering information on the disease and treatment options, and a clinical trials matching service. BMC Cancer 10:663.

19. Simon C, Schramm S, Hillis S: Patient internet use surrounding cancer clinical trials: clinician perceptions and responses. Contemp Clin Trials 2010, 31(3):229-234.

20. Rodrigues MJ, Haberer S, Dionysopoulos D, Barriere J, Wassermann J, Tazi Y, Rajpar S, Giroux J, Bidard FC, Loriot Y: Internet to boost patient accrual in oncology trials? A multiinstitutional AERIO study. Ann Oncol 2011, 22(2):490-491.

21. Carden CP, Jefford M, Rosenthal MA: Information about cancer clinical trials: an analysis of Internet resources. Eur J Cancer 2007, 43(10):1574-1580.

22. Simon C, Hegedus S: Exploring websites on cancer clinical trials: an empirical review. Contemp Clin Trials 2005, 26(5):530-533.

23. National Health and Medical Research Council and Consumers' Health Forum of Australia: A Model Framework for Consumer and Community 
Participation in Health and Medical Research. Australian Government; Canberra; 2005.

24. Oliver S, Clarke-Jones L, Rees R, Milne R, Buchanan P, Gabbay J, Gyte G, Oakley A, Stein K: Involving consumers in research and development agenda setting for the NHS: developing an evidence-based approach. Health Technol Assess 2004, 8(15).

25. Minogue V, Boness J, Brown A, Girdlestone J: The impact of service user involvement in research. Int $J$ Health Care Qual Assur Inc Leadersh Health Serv 2005, 18(2-3):103-112.

26. National Cancer Plan: a Plan for Investment, a Plan for Reform. Department of Health; London, United Kingdom; 2000.

27. Tallon D: Consumer involvement in research is essential. BMJ 2000, 320:380.

28. Bolchini D, Paolini P: Interactive dialogue model: a design technique for multichannel applications. Multimedia, IEEE Transactions on 2006, 8(3):529-541.

29. Kreuter MW, Oswald DL, Bull FC, Clark EM: Are tailored health education materials always more effective than non-tailored materials? Health Educ Res 2000, 15(3):305-315.

30. Australian Cancer Trials. [http://www.australiancancertrials.gov.au/].

31. Cancer Voices NSW. [http://www.cancervoices.org.au].

32. Saunders $C$, Crossing S, Girgis A, Butow P, Penman A: Operationalising a model framework for consumer and community participation in health and medical research. Aust New Zealand Health Policy 2007, 4:13.

33. Saunders C, Girgis A, Butow P, Crossing S, Penman A: From inclusion to independence - training consumers to review research. Health Research Policy and Systems 2008.

34. Annual Report in Cancer Australia Annual Report 2007-2008. Australian Government; Canberra; 2008.

35. Saunders C, Girgis A, Butow P, Crossing S, Penman A: Beyond scientific rigour: funding cancer research of public value. Health Policy 2007, 84(23):234-242.

36. CancerHelp UK. [http://www.cancerhelp.org.uk].

37. National Cancer Institute. [http://www.cancer.gov/clinicaltrials]

38. Google Analytics. [http://www.google.com/analytics/].

39. Health Insite. [http://www.healthinsite.gov.au/].

40. Brown RF, Butow PN, Dunn SM, Tattersall MH: Promoting patient participation and shortening cancer consultations: a randomised trial. $\mathrm{Br}$ J Cancer 2001, 85(9):1273-1279.

41. UK Clinical Trials Gateway. [http://www.ukctg.nihr.ac.uk/default.aspx].

42. International Standard Randomised Controlled Number Register. [http:// www.isrctn.org/].

43. Brown RFSE, Leighl N, Butow PN, Ostroff J, Edgerson S, Tattersall MHN: Enhancing decision making about participation in cancer clinical trials: Development of a Question Prompt List. Journal of Supportive Care in Cancer 2010.

44. Monaco V, Krills SK, Monaco V, Krills SK: On-line information about cancer clinical trials: evaluating the Web sites of comprehensive cancer centers. AMIA Annual Symposium Proceedings/AMIA Symposium 2003, 470-474.

45. Turning into digital goldfish. [http://news.bbc.co.uk/2/hi/science/nature/ 1834682.stm].

46. Zarin DA, Tse T, Williams RJ, Califf RM, Ide NC: The ClinicalTrials.gov Results Database Update and Key Issues. N Engl J Med 364(9):852-860.

47. Goodare H, Lockwood S: Involving patients in clinical research. BMJ 1999, 319(7212):724-725

48. United States Department of Defense Congressionally Directed Medical Research Programs (CDMRP). [http://cdmrp.army.mil].

49. Alzheimer's Society. [http://www.alzheimers.org.uk/site/scripts/documents. php?category|D=200296]

50. Cancer Council NSW. [http://www.cancercouncil.com.au/editorial.asp? pageid $=2229]$.

51. O'Donnell M, Entwistle V: Consumer involvement in research projects: the activities of research funders. Health Policy 2004, 69(2):229-238

52. National Health and Medical Research Council and Consumers' Health Forum: Statement on Consumer and Community Participation in Health and Medical Research (the Statement on Participation). Australian Government; Canberra; 2002.

doi:10.1186/1478-4505-9-30

Cite this article as: Dear et al: Consumer input into research: the

Australian Cancer Trials website. Health Research Policy and Systems 2011 9:30.

\section{Submit your next manuscript to BioMed Central and take full advantage of:}

- Convenient online submission

- Thorough peer review

- No space constraints or color figure charges

- Immediate publication on acceptance

- Inclusion in PubMed, CAS, Scopus and Google Scholar

- Research which is freely available for redistribution

Submit your manuscript at www.biomedcentral.com/submit
Biomed Central 